\title{
Lentiform fork sign in a uremic patient with a high anion gap metabolic acidosis with seizures: a case report from North West of Ireland
}

Salman Mansoor ${ }^{1 *}$ (D) Lize De Klerk1, James Lineen ${ }^{1}$, Muhammad Fahad ${ }^{1}$, Imran Ali', Barry Coffey ${ }^{1}$, Monica Ann Mulry', Shoab Saadat ${ }^{2}$, Siobhan Kelly', Mohammad Hijaz Adenan ${ }^{1}$ and Kevin Murphy ${ }^{1}$

\begin{abstract}
Background: Lentiform fork sign is a neuroradiological abnormality which is encountered in the clinical practice associated with uremic encephalopathy, dialysis disequilibrium syndrome and metabolic acidosis.

Case presentation: We describe here a case of this neuro-radiological abnormality which was encountered in a patient with uraemia and high anion gap metabolic acidosis who presented with generalised convulsion and later had some tremor in her hands. In our patient, there were few predisposing factors which might have possibly resulted in this abnormality chronic kidney disease, diabetes mellitus, and metabolic acidosis.

Conclusion: The Lentiform fork sign is a rare occurrence which can be related to a long list of toxic and metabolic causes but in conjunction with metabolic acidosis in chronic kidney disease patients, it can narrow down this list of alternate diagnosis.
\end{abstract}

Keywords: Lentiform fork sign, Uremic encephalopathy, Seizures, Anion gap, Status epilepticus

\section{Background}

Basal ganglia are metabolically highly active deep grey matter structures. There are various toxic and metabolic insults (uraemia, hypoxia, drug overdose, infections) that result in abnormalities in basal ganglia on neuroimaging [1-3]. The clinical features or uremic encephalopathy include tremors, chorea-athetoid movements, convulsions and coma in patients with renal diseases.

Lentiform fork sign is a neuroradiological abnormality which can be associated with uremic encephalopathy, dialysis disequilibrium syndrome and metabolic acidosis [3-5]. The sign is characterised by symmetrical hyperintensities in bilateral basal ganglia surrounded by hyperintense rim which delineates Lentiform nucleus $[2,3]$.

\footnotetext{
* Correspondence: salmanmansoor.dr@gmail.com

${ }^{1}$ Sligo University Hospital, Sligo, Ireland

Full list of author information is available at the end of the article
}

The underlying cause for which is postulated to be secondary to vasogenic edema.

We describe here a case of this neuro-radiological abnormality which was encountered in our patient with Uraemia and high anion gap metabolic acidosis who presented with a generalised convulsion and later had some tremor in her hands.

\section{Case presentation}

A 74-year-old lady with known CKD stage 3b was brought by ambulance to the emergency department after a first prolonged generalised tonic clonic seizure that lasted 90 minutes. On arrival she had a low Glasgow Coma Score (GCS) of 3/15. She was intubated and transferred to the intensive care unit. She had a history of diarrhoea and vomiting over the previous 7 days. Her family also reported her being fatigued over the previous week. 
Her past medical history also included hypertension, type 2 diabetes mellitus, osteoporosis, chronic obstructive pulmonary disease, anxiety disorder and benign paroxysmal positional vertigo.

Her regular medications at home included Venlafaxine $75 \mathrm{mg}$ once daily, Metformin $500 \mathrm{mg}$ twice daily, Zolpidem $10 \mathrm{mg}$ at night and Lercandipine $10 \mathrm{mg}$ once daily.

\section{Investigations}

Laboratory investigations on admission (Table 1) showed an acute kidney injury, with associated high anion gap metabolic acidosis. Her acidosis was attributed to a combination of lactate accumulation and acute renal failure. Serum ketones were not elevated. Neuroimaging done by CT-brain and MRI-brain are shown in Fig. 1.

Table 1 Showing blood Investigations at the time of arrival

\begin{tabular}{|c|c|c|}
\hline Electrolytes & Result & Reference ranges \\
\hline - Sodium & $137 \mathrm{mmol} / \mathrm{L}$ & 136-145 mmol/L \\
\hline - Potassium & $4.6 \mathrm{mmol} / \mathrm{L}$ & $3.5-5.1 \mathrm{mmol} / \mathrm{L}$ \\
\hline - Chloride & $97 \mathrm{mmol} / \mathrm{L}$ & 98-107 mmol/L \\
\hline - Bicarbonate & $9.2 \mathrm{mmol} / \mathrm{L}$ & $22.0-29.0 \mathrm{mmol} / \mathrm{L}$ \\
\hline - Blood glucose & $8.5 \mathrm{mmol} / \mathrm{L}$ & 3.9-7.1 mmol/L \\
\hline - Serum acetone & Negative & - \\
\hline \multicolumn{3}{|l|}{ Renal functions } \\
\hline - Blood urea & $39 \mathrm{mmol} / \mathrm{L}$ & $2.8-8.1 \mathrm{mmol} / \mathrm{L}$ \\
\hline - Creatinine & $657 \mathrm{umol} / \mathrm{L}$ & 45-84 umol/L \\
\hline $\begin{array}{l}\text { - Glomerular filtration } \\
\text { rate (GFR) }\end{array}$ & $5 \mathrm{ml} / \mathrm{min} / 1.73 \mathrm{sqm}$ & $>90 \mathrm{ml} / \mathrm{min} / 1.73 \mathrm{sqm}$ \\
\hline \multicolumn{3}{|l|}{ Arterial blood gases } \\
\hline$\cdot \mathrm{pH}$ & 7.04 & $7.35-7.45$ \\
\hline$\cdot \mathrm{HCO} 3$ & $9.2 \mathrm{mmol} / \mathrm{L}$ & $22.0-29.0 \mathrm{mmol} / \mathrm{L}$ \\
\hline$\cdot \mathrm{CO} 2$ & $4.5 \mathrm{kPa}$ & $4.27-6.40 \mathrm{kPa}$ \\
\hline .02 & $10.3 \mathrm{kPa}$ & $11.07-14.40 \mathrm{kPa}$ \\
\hline . O2 sats & $91.6 \%$ & \\
\hline - Lactate & $10.7 \mathrm{mmol} / \mathrm{L}$ & $1.0-1.8 \mathrm{mmol} / \mathrm{L}$ \\
\hline - Anion gap & $30.8 \mathrm{mmol} / \mathrm{L}$ & $12-15 \mathrm{mmol} / \mathrm{L}$ \\
\hline \multicolumn{3}{|l|}{ Full blood count } \\
\hline - White cell count & $12.410 * 9 / \mathrm{L}$ & $4.0-11.010^{*} 9 / \mathrm{L}$ \\
\hline - Heamoglobin & $7.3 \mathrm{~g} / \mathrm{L}$ & $11.5-16.5 \mathrm{~g} / \mathrm{L}$ \\
\hline - Platelets & $318,00010^{*} 9 / \mathrm{L}$ & $140-45010^{*} 9 / \mathrm{L}$ \\
\hline \multicolumn{3}{|l|}{ Liver function tests } \\
\hline - ALT & $8 \mathrm{U} / \mathrm{L}$ & 0-33 U/L \\
\hline • AST & $13 \mathrm{U} / \mathrm{L}$ & $0-32 \mathrm{U} / \mathrm{L}$ \\
\hline - Alk. phosp & $143 \mathrm{U} / \mathrm{L}$ & 35-105 IU/L \\
\hline • GGT & $23 \mathrm{U} / \mathrm{L}$ & $<40 \mathrm{U} / \mathrm{L}$ \\
\hline - Total bilirubin & $8 \mathrm{U} / \mathrm{L}$ & 0-15 umol/L \\
\hline - Total protein & $62 \mathrm{U} / \mathrm{L}$ & $66-87 \mathrm{~g} / \mathrm{L}$ \\
\hline
\end{tabular}

\section{Hospital course}

She was started on continuous veno-venous haemodiafiltration shortly after arrival in ICU and had a marked improvement in her laboratory figures at $24 \mathrm{~h}$. Lactate was cleared rapidly, and she required potassium supplementation.

During her admission in the intensive care unit, she had a CT scan of her brain followed 2 days later by MRI Brain which demonstrated the Lentiform fork sign. This sign can be best visualised on T2 and FLAIR Sequences that mainly signify edema.

She stayed in ICU for 3 days and was extubated on the second day of her admission due to her improving consciousness and hemodynamically stable condition.

There was a mild non-debilitating tremor that was observed in her hands which was present during both action and posture.

She was non-oliguric, and her serum bicarbonate and potassium remained within normal limits, but she had an inexorable rise in serum creatinine over the following weeks and is now maintained on intermittent haemodialysis.

She was discharged 6 weeks after her initial presentation. A follow-up at 6 months after her initial presentation, she had a complete resolution of her tremor, and there were no further seizures.

\section{Discussion}

There have been different toxic and metabolic derangements which are attributed to abnormalities in the basal ganglia [1]. The Lentiform fork sign is one such neuroimaging abnormality which is previously described related to chronic kidney disease.

In a case series of 11 patients with chronic kidney disease it was encountered commonly in patients who had metabolic acidosis at some point [2, 3]. Diabetes mellitus is reported to have some role in causation of this basal ganglia abnormality which our patient had however her blood glucose at the time of arrival was mildly deranged, the underlying mechanism has been postulated to be due to an underlying endothelial dysfunction in chronic diabetics [4-6].

In our patient, there were few predisposing factors which might have possibly resulted in this abnormality chronic kidney disease, diabetes mellitus and metabolic acidosis. The tremor that was observed could be due to the basal ganglia insult or just the direct effects of the renal derangements she presented with.

In our patient, the serum potassium was within the normal range despite several days of diarrhoea preceding admission. It is likely that her whole-body potassium stores were low, and her serum concentration reflected a degree of extracellular potassium shift in the face of metabolic acidosis, lack of insulin effect and possible alpha-adrenergic surge post seizure [7]. Her lactate level was presumed secondary to seizure and hypoxemia, but 


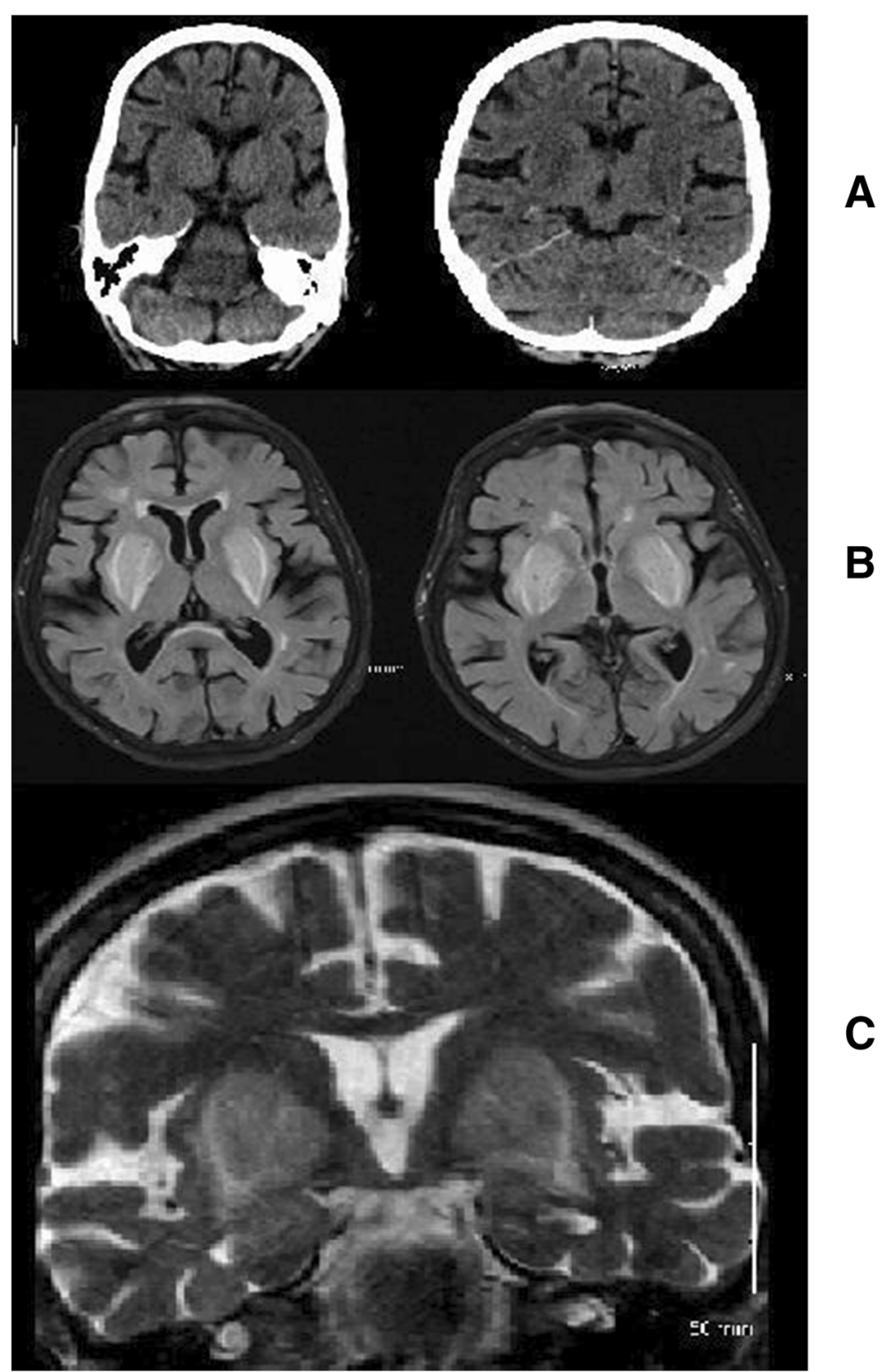

Fig. 1 Showing CT Scan and MRI Brain images. a CT-brain showing bilateral symmetrical hypodensity in the basal ganglia. b MRI Brain axial FLAIR sequence. c MRI brain coronal T2 sequences both showing bilateral symmetrical swollen lentiform nuclei with a hyperintense T2/FLAIR signal rim delineating the boundaries of the putamen

it should be noted that she was taking metformin prior to admission.

The pathophysiological basis for the basal ganglia abnormality is linked to vasogenic and cytotoxic edema [2]. The neuroimaging modalities CT brain and MRI brain reveal this neuroimaging abnormality and with aggressive dialysis and renal optimization these changes can be reversible [8]. Our patient did not undergo any further imaging to look for an interval difference.

\section{Conclusion}

The Lentiform fork sign is a rare occurrence which can be related to a long list of toxic and metabolic causes but in conjunction with metabolic acidosis in chronic kidney disease patients it can narrow down this list of alternate diagnosis.

\section{Acknowledgements}

We acknowledge the continuous support and encouragement of our medicine department at Sligo University Hospital. 


\section{Authors' contributions}

SM, LDK, JL and SS were involved in writing of manuscript diagnosing and treating the patient. Rest of the authors MF, IA, BC, MAM, SS, SK, MHA, JL and $\mathrm{KM}$ were involved in care and treatment of the patient. All authors have read and approved the manuscript.

\section{Funding}

N/A

\section{Availability of data and materials}

N/A

\section{Ethics approval and consent to participate}

N/A

\section{Consent for publication}

Written and Informed consent was obtained for this case report from the study participant

\section{Competing interests}

All authors declare no competing interests.

\section{Author details}

'Sligo University Hospital, Sligo, Ireland. ${ }^{2}$ Broomfield Hospital, NHS Trust, Essex, UK.

Received: 19 April 2020 Accepted: 2 October 2020

Published online: 14 October 2020

\section{References}

1. Albin RL. Basal ganglia neurotoxins. Neurol Clin. 2000:18(3):665-80.

2. Jaryal A, Thakur S, Pathania JS, Vikrant S, Kumar D, €€€Verma L. Lentiform fork sign: Uremia alone or multifactorial causation?. Hemodialysis International. 2020;24(1). https://doi.org/10.1111/hdi.12810.

3. Kumar G, Goyal MK. Lentiform Fork sign: A unique MRI picture. Is metabolic acidosis responsible? Clinical Neurology and Neurosurgery. 2010 Nov;112(9): 805-12.

4. Yoon CH, Seok JI, Lee DK, An GS. Bilateral basal ganglia and unilateral cortical involvement in a diabetic uremic patient. Clin Neurol Neurosurg. 2009 June; 111:477-9.

5. Lee EJ, Park JH, Ihn Y, Kim YJ, Lee SK, Park CS. Acute bilateral basal ganglia lesions in diabetic uraemia: diffusion-weighted MRI. Neuroradiology. 2007r 49:1009-13.

6. Wang HC, Hsu JL, Shen YY. Acute bilateral basal ganglia lesions in patients with diabetic uremia: an FDG-PET study. Clin Nucl Med. 2004 August;29: 475-8.

7. Nass RD, Sassen R, Elger CE, Surges R. The role of postictal laboratory blood analyses in the diagnosis and prognosis of seizures. Seizure. 2017 Apr:47:51-65.

8. Tajima Y, Mito Y, Yanai M, Fukazawa Y. Unusual basal ganglia lesions in a diabetic uraemic patient proven to be demyelination: first pathological observation. BMJ Case Rep. 2012;2012:bcr2012006522.

\section{Publisher's Note}

Springer Nature remains neutral with regard to jurisdictional claims in published maps and institutional affiliations.

\section{Submit your manuscript to a SpringerOpen ${ }^{\circ}$ journal and benefit from:}

- Convenient online submission

- Rigorous peer review

- Open access: articles freely available online

- High visibility within the field

- Retaining the copyright to your article 